\title{
A trilemma in social extrapreneurship?
}

Ana C. Aranda-Jan

Cambridge Center for Social Innovation (Cambridge Judge Business School)

a.arandajan@jbs.cam.ac.uk

There is growing interest in expanding our understanding of social innovation beyond social entrepreneurship to include addressing societal challenges through different decision-making levels and the collaboration of multiple actors (Seelos and Mair, 2018). Social extrapreneurship is a novel view of entrepreneurship; using a holistic approach is defined as multiple sectoral collaboration to tackle social challenges through innovative solutions. However, as appealing as it may be to understand social entrepreneurship as a more holistic approach, in practice, social change through multiple-actor collaboration comes with its challenges.

As I consider how challenging it is to generate social, political, and economic collaboration, I come to think that there is an apparent trilemma in social extrapreneurship that prevents it from fulfilling its promise. As actors from different sectors design, launch, and run collaborative action, their chances of failure increase if they find it difficult to reconcile different businesses in search of some compatibility between different businesses. A lack of collaboration results in opting for single sector intervention that turns social innovation into a less diverse and plural option. Actors often opt to strengthen the status quo and protect their own organization's businesses/interests even when they aimed to tackle social challenges together.

Complexity and uncertainty are common features of social innovation contexts. Therefore, in these contexts, organizations may stick to what they know best, if gains from collaborating with others are unclear. Moreover, a constant pivoting in their business models emerging from this same complexity and uncertainty has the potential to make collaboration even harder. Again, clarity in motivation and incentives is important. Failure will indicate that organizations are deciding to act individually. Social innovation is still possible. However, Kania and Kramer (2001) point that interventions from organisations in the social sector remains mainly within individual interventions.

\section{The promise of social extrapreneurship}


Tracey and Stott (2017) define social entrepreneurship as entrepreneurial action that combines resources, ideas, and people from different organisations and in different places towards addressing social challenges. This is a process that helps to recognize the complexity of social problems and a necessity to generate innovative solutions by relying on the intervention of multiple actors from different sectors. Often this capacity of actions is studied in social innovation research under the framework of cross-sectoral collaborative partnerships. Stott and Tracey (2018) point out that under increasing impetus, social innovation has come to consider cross-sectoral partnerships as a requirement for sustainable and systems solutions to social problems.

This impetus to support collaborative actions across sectors in the practice of social innovation is equally the result of market failures and a loss of trust in public institutions. Critics point to the limitation of single organizations acting alone as they try to address social challenges. It is argued that cross-sectoral collaborations are needed because, social challenges are too big and complex for single actor intervention. Kramer and Pfitzer (2016) argue that there is an expected promise of collective impact through collaborative action, as it is taken to be a result of a coordination of efforts in search of a common good while solving today's pressing social challenges.

Whilst there is optimism, I suggest that a pragmatic view is needed. Innovative action and implementation of a strategy are difficult to operationalize in cross-sectoral collaborations (Crosby and Bryson, 2010). Moreover, in cross-sectoral collaboration linearity in social entrepreneurial strategy is rare, as processes happen simultaneously, have overlaps, or are discontinuous in the context of great complexity (Stott et al., 2020). Social innovation requires a great degree of leadership and resources to move beyond the boundaries of single organizations (Pares et al., 2017). Coordination of actions is often more difficult if more than one actor participates in decision-making. Meanwhile, Cairns and Harris (2011) consider that enthusiasm is an essential first step in collaborative social innovation as organizations look to work together, however, it is not enough. Animosity between organizations arises as they have different assumptions, values, and beliefs; that is different institutional logic (Ashraf et al., 2017), in addition to different organisational structures, objectives, and missions. Thus, in the context of multiple sector collaboration with organisational diversity in a social innovation, cross-sectoral partnerships are difficult, in practice, we are not able to find many cases where we observe successful partnerships between the private, public and civil sectors. 


\section{From a trilemma to a social innovation paradox}

The difficult reconciliation for cross-sectoral collaboration towards solving social issues, brought me to think of Dani Rodrik's political economy trilemma (Figure 1). The trilemma that Roderik (2011) presents relates to the constant tensions he observes between a nation's interest for achieving globalization (i.e international trade, global markets), democracy (i.e. national policy, citizen's participation) and sovereignty (i.e. the nation-state). He argues that, whilst it is possible to combine any two of those elements, it is not possible to have all three simultaneously. Roderik's best option for globalisation is to sacrifice some measure of global economic integration in the interests of national sovereignty and democracy. In a post-capitalist era, a narrative supporting a reduction of nations' participation in global markets certainly has gained momentum and finds present expressions in some liberal or social nationalism in different countries. Whilst it would be misleading to present Rodrik's trilemma as support of the enlargement of the nation state, clarifying this point is not the aim here.

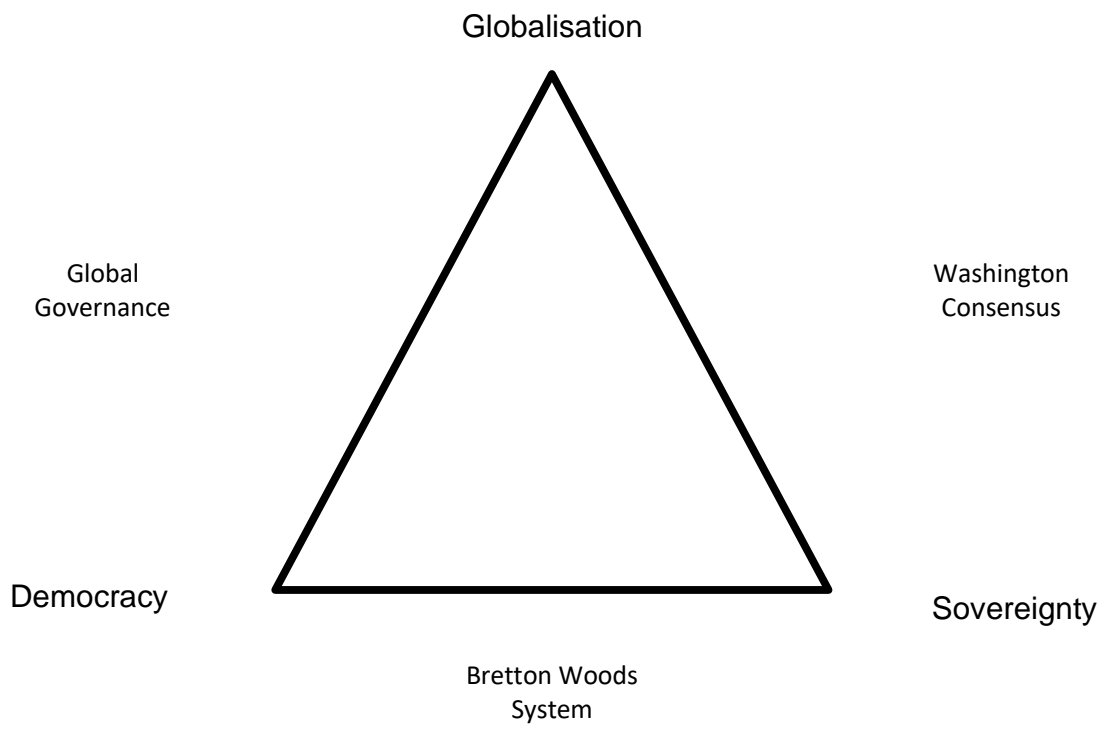

Figure 1. Rodrik's globalisation trilemma. Note: My elaboration.

By taking Rodrik's trilemma as an analogy, I wonder if a "reduction of the market" is also our best way forward for social innovation. Given that multiple sectoral collaborations are challenging, perhaps we should set our goal in promoting the participation of public and civil sectors in social innovation over private social innovative initiatives? 
I can accept that this is probably our best way forward. However, we may prefer relatively "equal" "competitive" and "sustainable" private, public, and civil sectors. Thus, a trilemma viewpoint for social innovation is incomplete (Figure 2). A lemma-proposition (i.e. dilemma, trilemma) form of thinking where an "either/or" solution to a problem is a dominant form, limits the possibility to understand social innovation collaboratively (Ziegler, 2017) i.e. either more state and less market, less state and more civil participation, "OR" other most likely dual combinations. Social innovation literature covers cases of public-private (e.g Whiteside, 2019), public-civil (e.g Toepler, 2018) and private-civil partnerships (e.g. Shier and Handy, 2016) and other cases focus in areas not fully explored like humanitarian-business partnerships (Nurmala et al., 2018). However, literature in social innovation looking at private-public-civil partnerships is less common. Assessing multiple actors' collaborations in social innovation, instead, needs to focus our attention on understanding the best possible balance between the private, public and civil sectors.

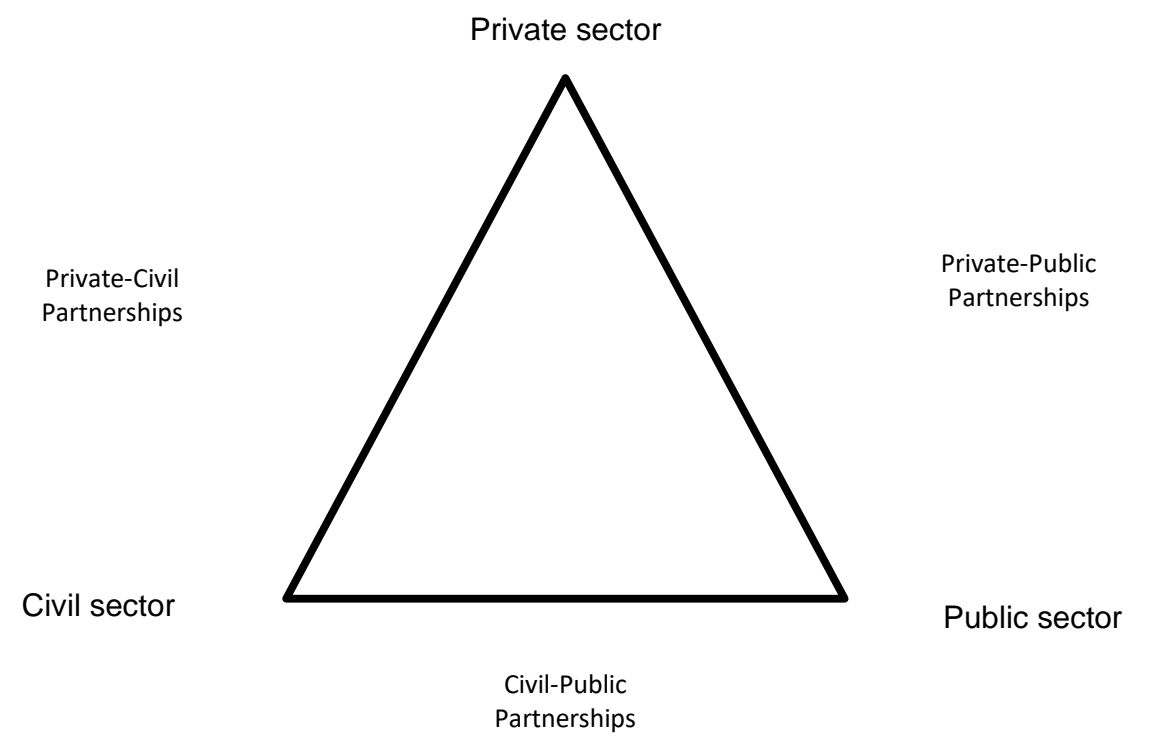

Figure 2. Trilemma of Social Innovation: an incomplete view of cross-sector collaboration. Note: My elaboration.

A starting point in finding and understanding our best balance in the practice of social innovation is to assume that there will always be competing demands between organisations and actors. Also, we may need to admit that private, public and civil sectors are always going to live together. Therefore, it is important to recognize that there are challenges for organizations in terms of how different institutional logics operate together when collaboration is needed. This creates tensions between organisations. The 
private sector is founded on competition and maximization of profit, while the public sector is about sustaining bureaucratic structures for redistribution and planning. Caring for others is a key principle in the organisation of civil society. Pearce and Kay (2003) clearly point out at differences in institutional logics by which individuals and organizations in different sectors have and provide meaning to their activities. There are different frames of social innovation actions across sectors. However, as we recognise the presence of these tensions, we can take a pragmatic approach must avoid trying to find a perfect combination. We just need to find our best possible balance.

A collaborative view of social innovation is then possible as we leave behind binary rationales. Social innovation finds the possibility to fulfil its promise under a "both/and" approach. A "both/and" rational is rooted in paradoxical thinking where persistent contradiction and interdependence between elements i.e. individuals, organisations, actors, sectors, persist over time. In a paradox approach, Smith and Tracey (2016) suggest that success depends on organizational capacity to address competing demands simultaneously and to seek strategies for managing conflict. For the case of multiple sectoral collaboration, embracing a paradoxical proposition suggests that while a presence of tensions in the practice of social innovation can push sectors to act individually, it is the acceptance of the presence of these tensions where the collaboration is possible in practice.

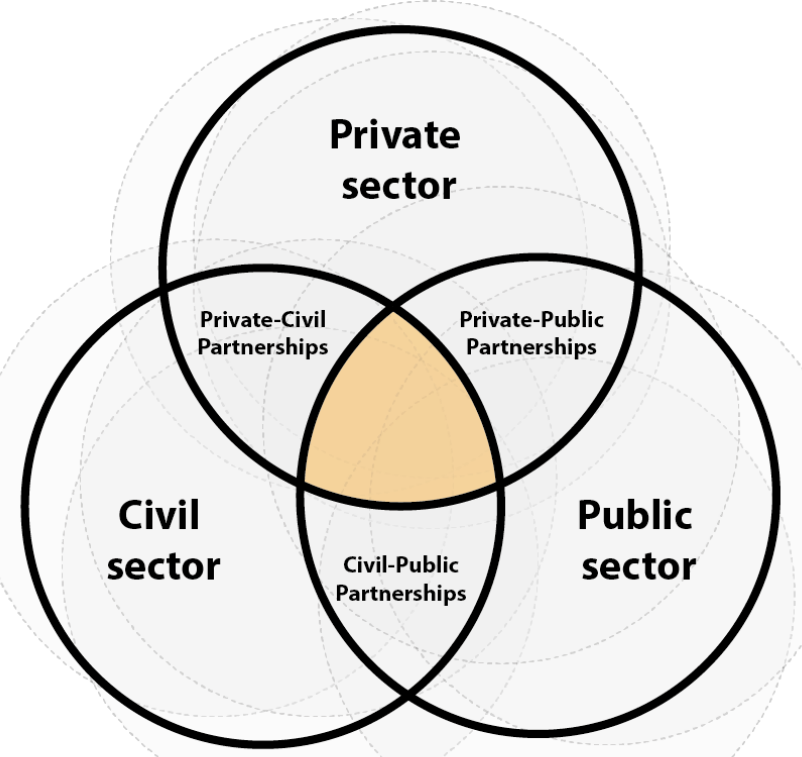

Figure 3. Multiple sectors collaboration in social innovation. Note: My elaboration. 
Private, public, and civil sectors exist together and at the same time (Figure 3). If we believe that social innovation is likely to find the best solutions when it originates through multiple actors, then we must recognise that innovative action will vary according to context and will not always generate a similar response.

\section{Conclusion:}

Decision-making in search of social innovation solutions becomes less about solving tensions in the form of tri/di-lemmas, trade-offs, or dichotomies and more about finding synergy and balance (central area in convergent circles in Figure 3). It is now possible to find an infinite number of combinations when referring to private-public-civil collaborations for social innovation practice. What is our best combination for social innovation? It will depend on the social issues, context and time.

As a final point, I admit that an underlying premise in my argument presents may favour supporting a governance model that enlarges the welfare state, which is much needed today, while I recognise a dynamic role of state and non-state actors that allows thinking about governance within the terms of complexity (Or and Aranda-Jan; 2017). As we look to different policy areas i.e. education, environment, economy, health; we are likely to get different optimal solutions for governance arrangements. Again, we get different configurations of multiple actor collaborations for social innovation. We left the challenge in identifying the strategies that help us find that balance between sectors in private-publiccivil collaborations; so far scholarship in social innovation has focused mainly in studying social enterprises or social entrepreneurship (e.g. Moizer and Tracey, 2010). 


\section{References:}

Ashraf, N., Ahmadsimab, A. and Pinkse, J. (2017), From Animosity to Affinity: The Interplay of Competing Logics and Interdependence in Cross-Sector Partnerships. Journal of Management Studies, 54: 793-822, doi:10.1111/joms.12273

Cairns, B. and Harris, M. (2011), Local cross-sector partnerships. Nonprofit Management and Leadership, 21: 311-324. doi: $10.1002 / \mathrm{nml} .20027$

Crosby, BC \& Bryson, JM 2010, Integrative leadership and the creation and maintenance of cross-sector collaborations. Leadership Quarterly, vol. 21, no. 2, pp. 211-230, doi.org/10.1016/i.leaqua.2010.01.003

Kania, J. and Kramer, M. (2011), Collective Impact. Sandford Social Innovation Review

Kramer, M. and Pfitzer, M. (2016), The Ecosystem of Shared Value. Harvard Business Review

Moizer, J. and Tracey, P. (2010), Strategy making in social enterprise: The role of resource allocation and its effects on organizational sustainability. Systems Research, 27: 252-266, doi.org/10.1002/sres.1006

Nurmala, N. de Vries, J. and de Leeuw, S. (2018), Cross-sector humanitarian-business partnerships in managing humanitarian logistics: an empirical verification. International Journal of Production Research, 56:21, 6842-6858, doi: 10.1080/00207543.2018.1449977

Or, N.H.K. and Aranda-Jan, A.C. (2017), The Dynamic Role of State and Nonstate Actors: Governance after Global Financial Crisis. Policy Studies Journal, 45: S67-S81. doi:10.1111/psj.12201

Pares, M., Sonia M. Ospina, S. M., and Subirats, J. (2017), Chapter 9: Learning from socially innovative initiatives and leadership practices in eds. Pares, M., Sonia M. Ospina, S. M., and Subirats, J. (2017), Social Innovation and Democratic Leadership: Communities and Social Change from Below. Cheltenham and Northampton: Edward Elgar

Pearce, J. and Kay, A. (2003), Social Enterprise in Anytown. London: Calouste Gulbenkian Foundation

Rodrik, D. (2011), The Globalization Paradox: Democracy and the Future of the World Economy. New York: W.W. Norton

Seelos, C. and Johanna Mair, J. (2018), Mastering System Change. Sandford Social Innovation Review

Shier M. L. and Handy, F. (2016), Cross-Sector Partnerships: Factors Supporting Social Innovation by Nonprofits. Human Service Organizations: Management, Leadership \& Governance, 40:3, 253-266, doi: $\underline{10.1080 / 23303131.2015 .1117556}$

Smith, W. and Tracey, P. (2016), Institutional complexity and paradox theory: Complementarities of competing demands. Strategic Organization, 14(4) 455-466 doi.org/10.1177/1476127016638565

Stott., N., Fava, M., Tracey, P. and Claus, L. (2020), Playing well with others? Community cross-sector work in poor places. Re-thinking Cross-Sector Social Innovation Conference, 6-7 
Stott, N. and Tracey, P. (2018), Organizing and innovating in poor places. Innovation, 20:1, 1-17, doi: $\underline{10.1080 / 14479338.2017 .1358093}$

Tracey, P. and Stott, N. (2017), Social innovation: a window on alternative ways of organizing and innovating. Innovation, 19:1, 51-60, doi: 10.1080/14479338.2016.1268924

Toepler, S. (2018), Public Philanthropic Partnerships: The Changing Nature of Government/Foundation Relationships in the US. International Journal of Public Administration, 41:8, 657-669, doi:

$\underline{10.1080 / 01900692.2017 .1295462}$

Whiteside, H. (2019), Public-private partnerships: market development through management reform, Review of International Political Economy. doi: 10.1080/09692290.2019.1635514

Ziegler, R. (2017), Social innovation as a collaborative concept. Innovation: The European Journal of Social Science Research, 30:4, 388-405, doi: 10.1080/13511610.2017.1348935 